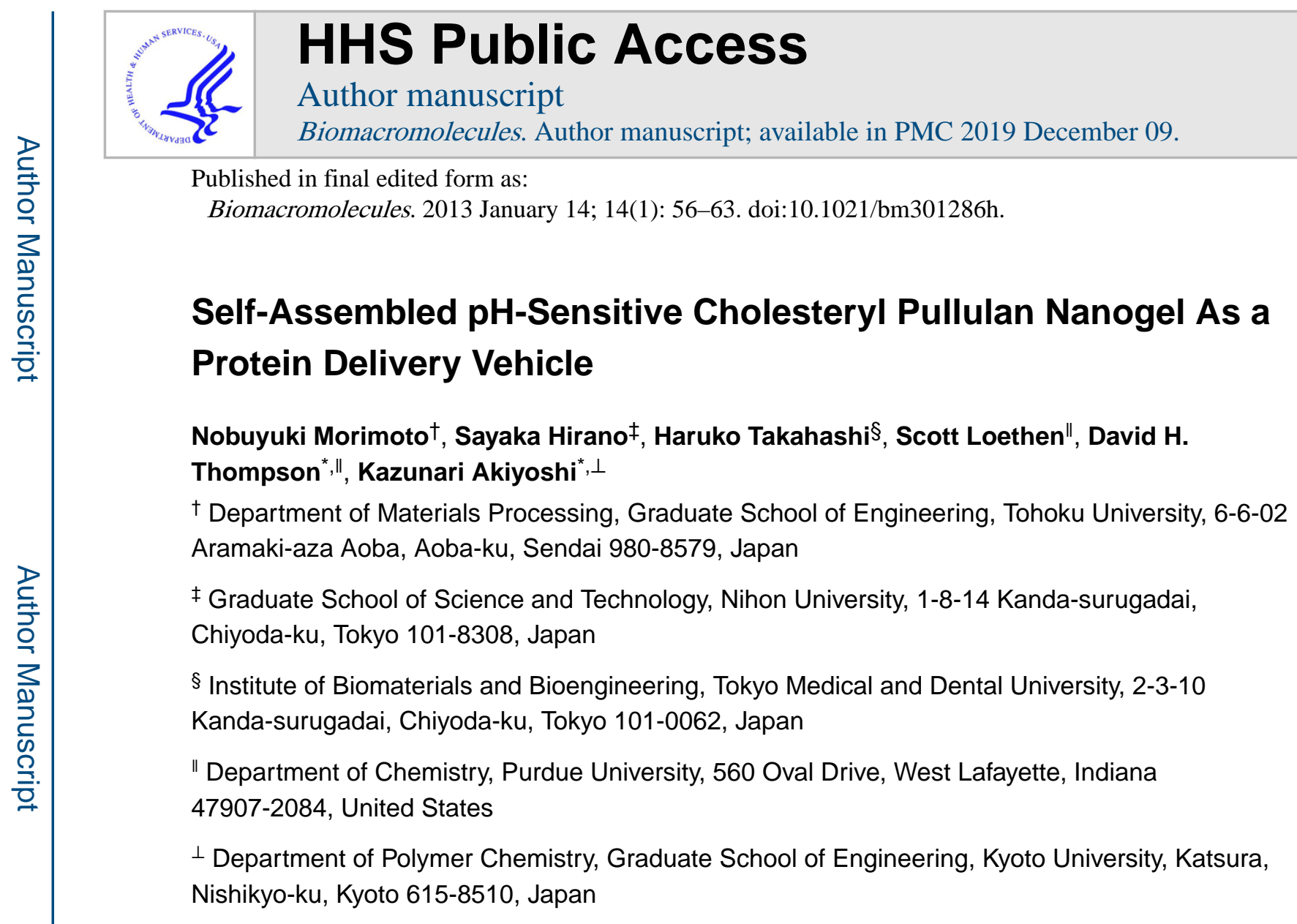

\title{
Abstract
}

A self-assembled nanogel, derived from an acidl-abile cholesteryl-modified pullulan (acL-CHP), was prepared by grafting vinyl ether-cholesterol substituents onto a $100 \mathrm{kD}$ pullulan main chain polymer backbone. Stable nanogels are formed by acL-CHP self-assemblies at neutral $\mathrm{pH}$. The hydrodynamic radius of the nanogels, observed to be $26.5 \pm 5.1 \mathrm{~nm}$ at $\mathrm{pH} 7.0$, increased by $\sim 135 \%$ upon acidification of the solution to $\mathrm{pH} 4.0$. SEC analysis of the acL-CHP nanogel at $\mathrm{pH}$ 4.0 showed that the grafts were nearly $80 \%$ degraded after $24 \mathrm{~h}$, whereas little or no degradation was observed over the same time period for a $\mathrm{pH}$ stable analog (acS-CHP) at $\mathrm{pH} 4.0$ or the acL$\mathrm{CHP}$ at $\mathrm{pH}$ 7.0. Complexation of BSA with the acL-CHP nanogel was observed at $\mathrm{pH} 7.0$ with subsequent release of the protein upon acidification. These findings suggest that stimuliresponsive, self-assembled nanogels can release protein cargo in a manner that is controlled by the degradation rate of the cholesterol-pullulan grafting moiety.

\section{Graphcial Abstract}

\footnotetext{
*Corresponding Author: akiyoshi@bio.polym.kyoto-u.ac.jp, Tel: +81-75-3832589, Fax: +81-75-383-2590 (K.A). davethom@ purdue.edu, Tel: 765-494-0386, Fax: 765-496-2592 (D.H.T.).

ASSOCIATED CONTENT

Supporting Information

${ }^{1} \mathrm{H}$ NMR spectrum of pullulan- $\mathrm{N}_{3}$ in DMSO- $d_{6},{ }^{1} \mathrm{H}$ NMR spectrum of acL-CHP in DMSO- $d_{6}$, and particle size histogram analyzed by TEM images of acL-CHP nanogel and acs-CHP nanogel. Estimation of hydrolyzed cholesterol in nanogel solutions at neutral and acidic condition. Cytotoxicity of acL-CHP nanogels.

This material is available free of charge via the Internet at http://pubs.acs.org.

The authors declare no competing financial interest.
} 


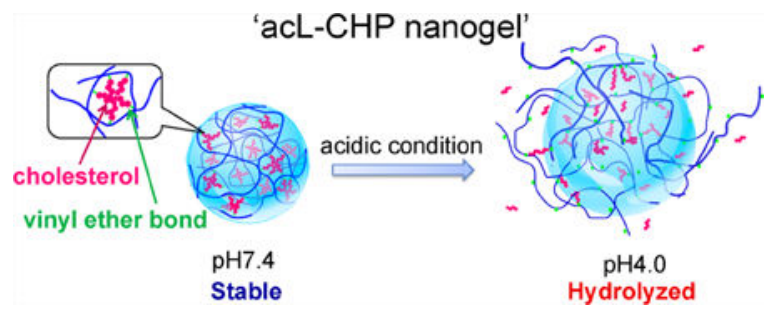

\section{INTRODUCTION}

Nanoparticle-based drug carriers are commonly used for encapsulating drugs to limit their adverse effects. In some cases, these vehicles have been designed to retain their drug cargo until they reach the target tissue, where a local stimulus promotes drug release. Recently, a number of advanced nanocarriers have been proposed that seek to impart both diagnosis and treatment using the same delivery vehicle. ${ }^{1-3}$ A major challenge in realizing this next generation of multifunctional nanocarriers will be the construction of systems that can package and release biomolecular cargo in an efficient manner as well as report on the local disease environment.

Nanometer-sized ( $<100 \mathrm{~nm}$ ) polymer hydrogels (nanogels) are interesting materials because of their capacity to serve as carrier systems for labile biomolecular cargo whose permeability can be varied as needed. ${ }^{4-7}$ A major challenge in designing multifunctional nanogels, however, is the size limitations that are encountered when cross-linking polymerization reactions are applied to their preparation. ${ }^{4,5}$ Self-assembled nanogels, prepared by dispersing various water-soluble polymers bearing hydrophobic substituents, have been developed as a means to obviate this problem. ${ }^{8-15}$ Akiyoshi and coworkers have developed cholesterol-bearing pullulan (CHP) nanogels, where the pullulan main chain is partially modified with cholesterol groups via an alkyl chain spacer. Several CHP molecules self-assemble to form monodisperse nanogels $(\sim 30 \mathrm{~nm})$ that are cross-linked by hydrophobic association of the cholesteryl groups of neighboring pullulan molecules. ${ }^{9,10}$ These CHP nanogels have also be shown to spontaneously form complexes with proteins or hydrophobic drugs. ${ }^{16}$ Moreover, the entrapped agents are released from the nanogel complex under conditions found in the bloodstream, cytosol, or other biological conditions. ${ }^{17} \mathrm{CHP}$ nanogels have been found to be an effective protein nanocarrier in vivo for bone formation and for vaccines targeted to tumors and mucosal tissue. ${ }^{18-21}$ Cationic CHP nanogels ${ }^{22}$ are also capable of delivering proteins intracellularly.

In this study, a new acid-labile CHP (acL-CHP) nanogel was developed that is stable under normal physiological $\mathrm{pH}$ conditions but degrades to release its cargo under acidic conditions (Figure 1). The acid-labile cholesterol derivative is tethered to the pullulan backbone by vinyl ether groups that are rapidly hydrolyzed in acidic media. An acL-CHP nanogel was prepared by a chemoselective 1,3-cycloaddition ("click") reaction between terminal alkyne groups present on the acid-labile cholesterol unit and azido groups incorporated within the modified pullulan main chain (Figure 2). 


\section{MATERIALS AND METHODS}

\section{Materials.}

All solvents were reagent grade, purchased from commercial sources, and used without further purification except THF. Pullulan $\left(M_{\mathrm{w}}=1.0 \times 10^{5}, M_{\mathrm{w}} / M_{\mathrm{n}}=1.7\right)$ was purchased from Hayashibara (Okayama, Japan). A cholesterol assay kit was purchased from Funakoshi (Tokyo, Japan). All other chemicals were obtained from Sigma-Aldrich (St. Louis, MO) and used without further purification. All ${ }^{1} \mathrm{H}$ NMR spectra were recorded on a Bruker $500 \mathrm{MHz}$ instrument. The chemical shifts are reported in $\delta$.

\section{Synthesis of Azido-Modified Pullulan (Pullulan- $\mathrm{N}_{3}$ ).}

Pullulan (3.00 g, $18.5 \mathrm{mmol}$ of glucose unit) was dissolved in DMSO $(150 \mathrm{~mL})$ in a dry three-necked flask, and 1,1' -carbonyldiimidazole ( $498 \mathrm{mg}, 3.08 \mathrm{mmol}$ ) was added at $25^{\circ} \mathrm{C}$. After $4 \mathrm{~h}, 3$-azidopropylamine $\left(2.78 \mathrm{mg}, 2.78 \times 10^{-2} \mathrm{mmol}\right)$ was added dropwise and stirred for $24 \mathrm{~h}$ at $25^{\circ} \mathrm{C}$. Then, the product was purified by dialysis and lyophilized to obtain the compound as a white solid. The degree of azide substitution on the pullulan main chain was 3.6 per 100 glucose unit. Yield: $2.94 \mathrm{~g}(98.0 \%)$. ${ }^{1} \mathrm{H}$ NMR (DMSO- $\left.d_{6} / \mathrm{D}_{2} \mathrm{O}=9 / 1, \mathrm{v} / \mathrm{v}\right): 1.68$ (s, $-\mathrm{NHCH}_{2} \mathrm{CH}_{2} \mathrm{CH}_{2} \mathrm{~N}_{3}$ ), 2.87-4.06 (m, glucose unit $2 \mathrm{H}, 3 \mathrm{H}, 4 \mathrm{H}, 5 \mathrm{H}$, and $6 H$ ), 4.57-4.75 (br, glucose unit $1 H(1-6)), 4.87-5.14$ (br, glucose unit $1 H(1-4)$ ).

\section{Synthesis of Prop-2-ynyloxy-acetic Acid t-Butyl Ester.}

$\mathrm{NaH}(4.58 \mathrm{~g}, 920 \mathrm{mmol})$ was dissolved in anhydrous THF $(300 \mathrm{~mL})$ in a dry flask at $0{ }^{\circ} \mathrm{C}$; then, propagyl alcohol $(10 \mathrm{~g}, 178 \mathrm{mmol})$ was added dropwise. After $1 \mathrm{~h}, t$-butyl bromoacetate $(31.7 \mathrm{~g}, 162 \mathrm{mmol})$ was slowly added at $0{ }^{\circ} \mathrm{C}$, and the reaction mixture was warmed to $25^{\circ} \mathrm{C}$ with stirring for $12 \mathrm{~h}$ before quenching with $\mathrm{H}_{2} \mathrm{O}$. The aqueous layer was extracted with ether, and the organic fractions were combined before washing with $\mathrm{H}_{2} \mathrm{O}$ and brine. The organic layer was dried over $\mathrm{MgSO}_{4}$ and filtered to remove $\mathrm{MgSO}_{4}$, and the filtrate was evaporated to produce an oil. Yield: $18.2 \mathrm{~g}(67.5 \%)$.

\section{Synthesis of 2-(Prop-2-ynyloxy)-acetic Acid.}

Prop-2-ynyloxy-acetic acid $t$-butyl ester $(18.23 \mathrm{~g}, 1.07 \mathrm{mmol})$ was dissolved in DCM ( $~ 80$ $\mathrm{mL}$ ) before adding trifluoroacetic acid $(36.4 \mathrm{~g}, 320 \mathrm{mmol})$ dropwise with stirring for $5 \mathrm{~h}$ at $25^{\circ} \mathrm{C}$. The reaction mixture was evaporated and purified by silica gel column chromatography using step gradient elution with DCM and $5 \% \mathrm{CH}_{3} \mathrm{CO}_{2} \mathrm{H}$ in DCM. Yield: $7.78 \mathrm{~g}(62.6 \%) .{ }^{1} \mathrm{H} \mathrm{NMR}\left(\mathrm{CDCl}_{3}\right): 2.56$ (t, $\left.\mathrm{CH}=\mathrm{CH}_{2}-\right), 4.27$ (s, $\left.-\mathrm{CCH}_{2} \mathrm{O}-\right), 4.32$ (d, $\left.-\mathrm{OCH} \mathrm{H}_{2} \mathrm{COOH}\right), 11.5(\mathrm{~s},-\mathrm{COOH})$.

\section{Synthesis of Acid Stable Cholesterol Derivative.}

$N, N^{\prime}$-Dicyclohexylcarbodiimide $(9.49 \mathrm{~g}, 46 \mathrm{mmol})$ was dissolved in $150 \mathrm{~mL}$ of DCM in a flame-dried flask. 2-(Prop-2-ynyloxy)-acetic acid $(4.00 \mathrm{~g}, 34.5 \mathrm{mmol})$ was added at $0{ }^{\circ} \mathrm{C}$ and stirred $10 \mathrm{mi}$ n before adding cholesterol $(8.48 \mathrm{~g}, 23.0 \mathrm{mmol})$ and $N, N^{\prime}$ -

dimethyl-4aminopyridine $(0.42 \mathrm{~g}, 3.45 \mathrm{mmol})$. The mixture was warmed to $25^{\circ} \mathrm{C}$ and stirred for $12 \mathrm{~h}$. After quenching with water, the aqueous phase was extracted with hexane, and the organic fractions were combined prior to washing with $\mathrm{H}_{2} \mathrm{O}$ and brine and drying 
with $\mathrm{MgSO}_{4}$ and evaporation to give a crude product that was purified by silica gel column chromatography using 60:40 DCM/hexane as eluent. Yield: $8.67 \mathrm{~g} \mathrm{(52.1 \% ).}{ }^{1} \mathrm{H}$ NMR $\left(\mathrm{CDCl}_{3}\right): 0.65(s$, cholesterol, 3H) 0.78-2.05 ( $\mathrm{m}$, cholesterol 51 H), $2.35(\mathrm{~d}, 2 \mathrm{H}),$,2.47 ( $t$, $1 \mathrm{H}), 4.17(s, 1 H), 4.38(d, 1 H), 4.72(m, 1 H), 5.38(d, 1 H)$.

\section{Synthesis of Acid-Labile Cholesterol Derivative.}

The acid stable cholesterol derivative ( $500 \mathrm{mg}, 1.04 \mathrm{mmol}, 1$ equiv) was dissolved in $15 \mathrm{~mL}$ of toluene/THF/pyridine (1/1/1 by vol.) in a flame-dried flask and cooled to $-30{ }^{\circ} \mathrm{C}$ before adding Tebbe reagent $(5.00 \mathrm{~mL}$ of $0.5 \mathrm{M}$ solution in toluene, $3.80 \mathrm{mmol}, 3.65$ equiv) dropwise and stirred for $30 \mathrm{~min}$ at $-30{ }^{\circ} \mathrm{C}$. Then, the mixture was warmed to $25{ }^{\circ} \mathrm{C}$ and stirred for an additional $90 \mathrm{~min}$ before quenching at $-10{ }^{\circ} \mathrm{C}$ with $1.0 \mathrm{~mL}$ of $15 \% \mathrm{NaOH}$ aqueous solution and $50.0 \mathrm{~mL}$ of diethyl ether and allowing the mixture to warm to $25^{\circ} \mathrm{C}$. After $1 \mathrm{~h}$, the solution was diluted with excess diethyl ether and DCM, and the solution was filtered through a Celite pad. The reaction products were purified by a neutralized silica gel column chromatography using 1:1 DCM/hexane $+1 \% \mathrm{Et}_{3} \mathrm{~N}$ as eluent. Yield: $109 \mathrm{mg}$ (21.8\%). ${ }^{1} \mathrm{H}$ NMR $\left(\mathrm{CDCl}_{3}\right): 0.68$ (s, cholesterol 21-3H) 0.78-2.08 (m, cholesterol $H$ ), 2.23 (m, 2H), $2.42(\mathrm{~m}, 1 H), 3.87(\mathrm{~m}, 1 H), 3.98(\mathrm{~s}, 2 H), 4.10(\mathrm{~d}, 1 H), 4.19$ (d, 2H), $4.23(\mathrm{~d}, 1 H)$, $5.37(\mathrm{~m}, 1 s) . \mathrm{MS}=503.3[\mathrm{M}+\mathrm{Na}]$.

\section{Synthesis of Acid-Labile Cholesterol Derivative Bearing Pullulan (acL-CHP) via Click Reaction.}

Pullulan- $\mathrm{N}_{3}(357 \mathrm{mg}, 2.20 \mathrm{mmol}$ of glucose unit, 1.00 equiv, degree of substitution $=3.6$ azide units per 100 glucose units) and the acid-labile cholesterol derivative $(70.0 \mathrm{mg}, 0.146$ mmol, $6.6 \times 10^{-2}$ equiv) were dissolved in $35 \mathrm{~mL}$ of DMF. Freshly prepared aqueous sodium ascorbate ( $36.5 \mu \mathrm{L}, 1.00 \mathrm{M}, 20 \mathrm{~mol} \%, 0.50$ equiv), aqueous copper(II) sulfate pentahydride ( $25.5 \mu \mathrm{L}, 1.0 \mathrm{M}, 10 \mathrm{~mol} \%, 0.35$ equiv), and triethylamine $(3.0 \mathrm{~mL})$ were added and stirred at $40{ }^{\circ} \mathrm{C}$ for 5 days. The product was isolated by three cycles of precipitation-dissolution-reprecipitation using 9:1 diethyl ether/ethanol as a poor solvent, and the precipitate was gathered by centrifugation $\left(3000 \mathrm{rpm}, 5 \mathrm{~min}\right.$ at $\left.4{ }^{\circ} \mathrm{C}\right)$. The precipitate was dissolved in DMSO at $10 \mathrm{mg} / \mathrm{mL}$ before dialyzing $(\mathrm{MWCO}=3500)$ against $\mathrm{H}_{2} \mathrm{O}$ for 4 days and then lyophilizing to give a white powder. The degree of substitution of acid-labile cholesterol in pullulan was 1.66 per 100 glucose units. Yield: $360 \mathrm{mg}(96.1 \%) .{ }^{1} \mathrm{H}$ NMR (9:1 DMSO- $d_{6} / \mathrm{D}_{2} \mathrm{O}, \mathrm{v} / \mathrm{v}$ ): 0.64-2.28 (cholesterol $H$ ), 1.61-1.76 (br, $-\mathrm{NHCH}_{2} \mathrm{CH}_{2} \mathrm{CH}_{2} \mathrm{~N}_{3}$ ), 2.87-4.20 (m, glucose unit $2 H, 3 H, 4 H, 5 H$, and 6H), 4.62-4.84 (br, glucose unit $1 H(1-6)$ ), 4.87-5.22 (br, glucose unit $1 H(1-4))$.

\section{Preparation of acL-CHP Nanogel Solution.}

acL-CHP was dispersed at a concentration of $2.0 \mathrm{mg} / \mathrm{mL}$ in citric acid-phosphoric acid mixed buffer at $\mathrm{pH} 7.4$ (C/P buffer: $88 \mathrm{mM}$ citric acid, $5.5 \mathrm{mM}$ phosphoric acid, $137 \mathrm{mM}$ $\mathrm{NaCl}$ ) and stirred for 1 day. Then, the solution was ultrasonicated for $15 \mathrm{~min}$ at $30 \mathrm{~W}$ using a probe-type sonicator before centrifuging the sample at $1.9 \times 10^{4} \mathrm{~g}$ for $30 \mathrm{~min}$ and filtering the supernatant through a $0.22 \mu \mathrm{m}$ PVDF membrane filter to obtain the acL-CHP nanogel. The concentration of the acL-CHP nanogel solution was determined by quantitative glucose analysis using the phenol-sulfate method. For acid-catalyzed hydrolysis experiments, citric acid buffer $(0.10 \mathrm{M}, \mathrm{pH} 1.9)$ was added to the nanogel solution at $\mathrm{pH} 7.4$ to produce a final 
solution $\mathrm{pH}$ of 4.0. Control experiments using acid-stable CHP (acS-CHP) nanogels (i.e., cholesterol-pullulan with no vinyl ether groups) were prepared using pullulan- $\mathrm{N}_{3}$ and the acid-stable cholesterol derivative.

\section{Dynamic Light Scattering Measurements.}

Dynamic light scattering (DLS) measurements were carried out with a Zetasizer Nano ZS instrument (Malvern Instruments, Malvern, U.K.) operating at a wavelength of $632.8 \mathrm{~nm}$ and a $173^{\circ}$ detection angle equipped with a Peltier temperature control unit. The hydrodynamic radius of nanogels was determined with a Laplace inversion program (CONTIN).

\section{Size Exclusion Chromatography-Multi-Angle Laser Light Scattering Measurements.}

Size exclusion chromatography (SEC) was performed on a chromatography system using an RI-8020 refractive index detector (Tosoh Corporation) connected to multiangle laser light scattering (MALS) detector (DAWN DSP, Wyatt Technology). Sephacryl S-500 10/300 was used as the column for SEC-MALS measurements. Nanogel solutions $(2.0 \mathrm{mg} / \mathrm{mL})$ were eluted with $\mathrm{pH} 7.4 \mathrm{C} / \mathrm{P}$ buffer with a flow rate of $0.50 \mathrm{~mL} / \mathrm{min}$ at $25^{\circ} \mathrm{C}$. The molecular weight $\left(M_{\mathrm{w}}\right)$ was determined using ASTRA software based on Zimm's equation. The refractive index increment $(\mathrm{d} n / \mathrm{sdc})$ was determined by an Optilab DSP differential refractometer operating at $690 \mathrm{~nm}$. The value of $\mathrm{d} n / \mathrm{dc}$ for pullulan was $0.142 \mathrm{~mL} / \mathrm{g}$.

\section{Transmission Electron Microscopy Observation of acL-CHP Nanogel.}

A $5.00 \mu \mathrm{L}$ sample of nanogel solution was deposited onto a carbon-coated copper grid before negatively staining with $5.00 \mu \mathrm{L}$ of $2.5 \%$ phosphotungstic acid for $5 \mathrm{~min}$.

Transmission electron microscopy (TEM) analysis was performed on an H-600 microscope (Hitachi, Tokyo, Japan) at an accelerating voltage of $75 \mathrm{kV}$.

\section{Quantification of Hydrolyzed Cholesterol From acL-CHP Nanogel.}

The acL- and acS-CHP nanogel solutions were prepared in pure water before bubbling $\mathrm{CO}_{2}$ gas into the nanogel solution until the $\mathrm{pH}$ reached 4.0. After $24 \mathrm{~h}$, the test solution was lyophilized and redissolved in DMSO. The quantity of hydrolyzed cholesterol in the acL-or acS-CHP nanogel solution was determined by cholesterol assay kit (Funakoshi, Tokyo, Japan).

\section{Evaluation of Complexes Formed between acL-CHP Nanogel and Protein by SEC.}

As a model protein, fluorescein isothiocyanate-labeled bovine serum albumin (FITC-BSA, $20 \mu \mathrm{M})$ was dissolved in C/P buffer. Nanogel solutions were mixed with FITC-BSA solution at pH 7.4. After $5 \mathrm{~min}, 2 \mathrm{~h}, 4 \mathrm{~h}, 6 \mathrm{~h}$, and $26 \mathrm{~h}$ of mixing, the mixture (final concentration of glucose unit in pullulan: $2.0 \mu \mathrm{M}$ ) was measured by SEC. SEC elution was monitored by RI and UV (494 nm). Acid-catalyzed hydrolysis of acL-CHP nanogel in nanogel/FITC-BSA complex and the release of FITC-BSA from the complex were also tracked by GPC after the citric acid buffer $(0.10 \mathrm{M})$ addition to obtain $\mathrm{pH} 4.0$ complex solution. 


\section{RESULTS AND DISCUSSION}

\section{Design and Synthesis of Acid Labile Cholesterol Bearing Pullulan.}

Thompson and coworkers have shown that vinyl ether conjugates of the type used in the acL-CHP construct are stable for days at neutral $\mathrm{pH}$ but are readily hydrolyzed at lower $\mathrm{pH}$ conditions $(\mathrm{pH}<5) .{ }^{23,24}$ Liposomes derived from acid-labile lipids bearing vinyl ether bonds were shown to undergo enhanced cargo release upon exposure to acidic $\mathrm{pH}$ media. ${ }^{25,26} \mathrm{Xu}$ et al. have also reported that PEGylated phospholipids containing vinyl ether bonds display a lower cytotoxity and higher transfection efficiency via a dePEGylation mechanism than the commercially available cationic lipid, lipofectamine. ${ }^{27}$ Polyrotaxanes bearing cleavable cholesterol end-caps have also been prepared using the click reaction and shown to undergo $\mathrm{pH}$-dependent dethreading of the polyrotaxane structure. ${ }^{28}$ On the basis of these previous findings, we sought to prepare an acid-labile cholesteryl vinyl ether linkage by methylidination of a cholesteryl ester precursor via the Tebbe reaction (Scheme 1). ${ }^{29,30}$ This reaction sequence also used the click reaction to install the acid labile cholesteryl vinyl ether pendant groups under mild conditions. This was achieved by modifying pullulan with azide groups using a $1,1^{\prime}$-carbonyldiimidazole ${ }^{22}$ coupling sequence to generate a product with a degree of azide group substitution on the pullulan main chain of 3.6 per 100 glucose unit (Figure S1 of the Supporting Information). Click-mediated installation of the acid-labile cholesteryl vinyl ether pendant group onto the pullulan- $\mathrm{N}_{3}$ scaffold generated a product containing 1.7 cholesterol units per 100 pullulan glucose units (Figure S2 of the Supporting Information). A cholesteryl ester linked pullulan derivative was also prepared as a control compound, yielding a product bearing 1.5 cholesterol units per 100 pullulan glucose units. These degrees of substitution translate to $\sim 11$ cholesteryl vinyl ether pendant groups and $\sim 10$ cholesteryl ester pendant groups per pullulan molecule, respectively. These degrees of cholesterol substitution were sought to avoid self-aggregation and promote the formation of monodispersed nanogels via intermolecular cross-linking via hydrophobic association of the cholesterol pendant groups. ${ }^{10}$

\section{Solution Properties of acL-CHP Nanogels at Physiological pH.}

The solution properties of the acL-CHP derivative were evaluated to determine whether it could self-assemble to form a nanogel under physiological conditions. SEC-MALS analysis was used to measure the association properties of ac-LCHP in C/P buffer at pH 7.4 (Table 1). Because the molecular weight of pullulan starting material was $1.0 \times 10^{5}$, we infer that $\sim 10$ molecules of acL-CHP are associated to form the nanogel particles. The size of the nanogels was then evaluated by DLS measurements. The hydrodynamic radius of the acLCHP nanogel samples was found to be $26.5 \mathrm{~nm}$, with the polydispersity index of 0.25 . Similarly, the acS-CHP control polymer also formed nanogels with $\sim 11$ molecules per particle, with a hydrodynamic radius of $18.4 \mathrm{~nm}(\mathrm{PDI}=0.22)$. The polymer density within the nanogels $\left(\Phi_{H}\right)$ can be calculated from $R_{H}$ and $M_{W}$ according to eq 1

$$
\Phi_{\mathrm{H}}=\left(\frac{\mathrm{M}_{\mathrm{W}}}{\mathrm{N}_{\mathrm{A}}}\right)\left(\frac{4}{3} \pi \mathrm{R}_{\mathrm{H}}\right)^{-1}
$$


where $N_{\mathrm{A}}$ is Avogadro's number. The $\Phi_{H}$ of acL-CHP and acS-CHP nanogels were 0.024 and 0.071 , respectively, suggesting that the nanogels were composed of $\sim 98$ and $\sim 93 \%$ water for the acL-CHP and acS-CHP nanogels, respectively. The density of nanogel affects the release rate of trapped protein. The complex between higher density of nanogel and protein was more stable and enabled longer continuous release compared with that of lower density nanogel. ${ }^{13}$ Comparison with other CHP nanogels ${ }^{10}$ was prepared from the same molecular weight of pullulan starting material, indicating that these nanogels displayed larger association numbers, molecular weight distributions, and hydrodynamic radii. We attribute these differences to the different spacer moieties that were used to attach the cholesteryl pendant groups in the acL- and acS-CHP materials and suggest that control of the spacer chain length, hydrophobicity, and steric properties may provide the capacity to design novel "self-assembled" nanogels with more diverse characteristics. Figure 3 shows the negatively stained TEM images of the acL-CHP and acS-CHP nanogels. Both acL-CHP and acS-CHP nanogels were observed as spherical nanoparticles, with the diameter of 12.3 \pm 3.3 and $16.4 \pm 2.5 \mathrm{~nm}$, respectively (Figure S3 of the Supporting Information).

\section{Acid-Catalyzed Hydrolysis.}

Nanogel solutions prepared in $\mathrm{pH} 7.4$ physiological buffer were acidified to $\mathrm{pH} 4.0$ by the addition of citric acid buffer of higher buffer capacity and the time course of nanogel degradation monitored by DLS and SEC analysis. Figure 4 shows the swelling behavior of the ac-LCHP and acS-CHP nanogels upon exposure to $\mathrm{pH} 4.0$ as determined by DLS. The swelling ratio of acL-CHP nanogels gradually increased under acidic conditions until the swelling ratio reached $135 \%$ after $8 \mathrm{~h}$ relative to the initial $\mathrm{pH} 7.4$ conditions, even though acS-CHP nanogels did not change in size upon exposure to $\mathrm{pH}$ 4.0. Interestingly, the polydispersity indices of both types of nanogels ( $\mathrm{PDI}=\sim 0.2$ ) remained unchanged. We infer that weak interactions between partially hydrolyzed acL-CHP molecules are responsible for the modest increase in hydrodynamic radius of the acL-CHP nanogel dispersions (Figure 4a).

SEC-RI analysis of acidic acL-CHP nanogel solutions revealed the presence of two peaks (Figure 5), a sharp peak at $R_{\mathrm{T}}=14-17 \mathrm{~min}$, and a comparatively broad peak at $R_{\mathrm{T}}=17-26$ $\mathrm{min}$. The first peak was attributed to the intact nanogel assemblies, and the second peak was attributed to the modified pullulan unimers. The peak area corresponding to the nanogel form of acL-CHP in Figure 5 was plotted as a function of time (Figure 4b). Although the acS-CHP nanogel peak area remained unchanged over $24 \mathrm{~h}$, the acL-CHP nanogel peak area gradually decreased to $\sim 35 \%$ of the initial magnitude. The second SEC peak is due to fully hydrolyzed and partially hydrolyzed acL-CHP molecules derived from the acL-CHP nanogels that were retarded by the SEC column. We infer from these results that the acLCHP derivative gradually lost its ability to form nanogels via cleavage of the cholesteryl vinyl ether bond. This hypothesis was tested by monitoring for the appearance of cholesterol after exposure to $\mathrm{pH} 4.0$ for $24 \mathrm{~h}$ via cholesterol oxidase assay. ${ }^{31}$ Very low levels $(\sim 0.02 \%)$ of free cholesterol were found in the acS-CHP nanogel solutions under neutral and acidic conditions (Figure S4 of the Supporting Information), whereas $18.2 \pm 7.1$ and $3.9 \pm 0.9 \%$ free cholesterol were found in acL-CHP nanogel solutions that had been exposed for $24 \mathrm{~h}$ to pH 4.0 and 7.4, respectively. The degradation rate of acL-CHP nanogels was much slower 
than we expected, however, based on previous work showing that the cholesteryl vinyl ether group was hydrolyzed $(\sim 1 \mathrm{~h})$ rapidly under acidic conditions. ${ }^{23-25}$ Intramolecular trapping of the protonated vinyl ether to produce a more stable acetal intermediate is proposed as the basis for the observed reaction kinetics for acL-CHP nanogels (Figure 6). Even though acetals are cleaved by an acid-catalyzed hydrolysis mechanism, their reaction kinetics are much slower than vinyl ethers of similar structure.

\section{Interaction between acL-CHP Nanogels and Protein Cargo.}

CHP nanogels have been reported as effective protein carriers; ${ }^{8,16,18-22}$ therefore, acL-CHP nanogels were also evaluated for their ability to serve as protein delivery vehicles. The complexation and release behavior between acL-CHP nanogel and a model protein cargo was studied using fluorescently labeled FITC-BSA. Complex formation between acL-CHP nanogels and FITC-BSA was also evaluated using GPC with dual detection by RI and UVvis detection at $494 \mathrm{~nm}$ (fluorescein). Figure 7 shows a GPC chromatogram of an acL-CHP nanogel/FITC-BSA mixture at $\mathrm{pH}$ 7.4. Two peaks were observed: the first peak at $R_{\mathrm{T}}=14$ $17 \mathrm{~min}$ (acL-CHP nanogel/FITC-BSA complex) and the second at $R_{\mathrm{T}}=21-25 \mathrm{~min}$ (free FITC-BSA). After $2 \mathrm{~h}$, more than $80 \%$ of the FITC-BSA in solution was complexed with the acL-CHP nanogel fraction in this condition. Complexes formed in this manner were stable for at least $24 \mathrm{~h}$ in $\mathrm{C} / \mathrm{P}$ buffer ( $\mathrm{pH} 7.4,25^{\circ} \mathrm{C}$ ). Protein release from these nanogels was then evaluated by acidifying these acL-CHP/protein complexes.

Figure 8 shows GPC chromatograms (RI and UV detection) of the complex after treatment at $\mathrm{pH} 4.0\left(25^{\circ} \mathrm{C}\right)$. RI detection reveals that the acL-CHP/protein peak area at $R_{\mathrm{T}}=14-17$ min gradually decreased, implying that the acL-CHP nanogel in the complex was hydrolyzed. The hydrolysis rate of the complex was slower than that of the acL-CHP nanogel alone. UV detection of the GPC traces also produced two peaks at $R_{\mathrm{T}}=14-17 \mathrm{~min}$ and $R_{\mathrm{T}}=21-25 \mathrm{~min}$, corresponding to acL-CHP/ FITC-BSA nanogel complexes and free FITC-BSA at $R_{\mathrm{T}}=21-25 \mathrm{~min}$ arising from acid-catalyzed hydrolysis of the complexes. The peak area of free FITC-BSA increased after acid-catalyzed hydrolysis of acL-CHP nanogel, suggesting that $\sim 27 \%$ of the FITC-BSA was released from the complex upon exposure to $\mathrm{pH} 4.0$ within $26 \mathrm{~h}$ via acid-catalyzed hydrolysis of the ac-LCHP nanogel and release of the trapped FITC-BSA. Because the observed BSA release rate was slower than the acL-CHP hydrolysis rate, we propose several reasons why much of the BSA remains associated with the acL-CHP nanogel. At $\mathrm{pH}$ 4.0, BSA exhibits a reversible N-F transition via an intermediate form, ${ }^{32}$ whose structure is expanded to an extent that it may have difficulty diffusing through the majority of the pores present in the nanogel. Second, CHP nanogels form complexes more easily with partially denatured proteins, possibly contributing to enhanced nanogel stability with the BSA intermediate formed $\mathrm{pH} 4.0 .{ }^{33}$ Finally, the formation of acetal byproducts from intramolecular trapping of the protonated cholesteryl vinyl ether hydrolysis intermediate may generate protein-nanogel complexes that release the BSA cargo much more slowly under acidic conditions. One or more of these factors may explain why there appears to be an increased affinity between partially hydrolyzed acL-CHP nanogel and BSA under acidic conditions. Further experiments are required to distinguish between these mechanistic possibilities. 


\section{CONCLUSIONS}

We succeeded in preparing acid-labile nanogels via aqueous self-assembly of pullulan derivatives bearing acid cleavable cholesterol moieties. These acL-CHP nanogels remain stable at physiological $\mathrm{pH}$ but are hydrolyzed at $\mathrm{pH} 4.0$ on the hours-to-days time scale. They also rapidly form protein complexes that retain the protein cargo at $\mathrm{pH} 7.4$ and release it under acidic conditions on the days time scale. We have already confirmed the low cytotoxicity of acL-CHP nanogel (Figure S5 of the Supporting Information). These materials are one type of novel stimuli-responsive amphiphilic polymers in a growing family of $\mathrm{pH}-,{ }^{34}$ heat-,${ }^{35-37}$ and light- ${ }^{38}$ sensitive nanogels that may be effective building blocks for the production of multifunctional hybrid nanogels for cellular delivery and tissue engineering applications.

\section{Supplementary Material}

Refer to Web version on PubMed Central for supplementary material.

\section{ACKNOWLEDGMENTS}

We thank Dr. Aditya Kulkarni (Purdue University) for cytotoxicity test of the polymers. K.A. and N.M. acknowledge the funding support for this work by Grants-in-Aid for Scientific Research (\#20240047, \#22114009, and \#22680039) from the Japan Society for the Promotion of Science (JSPS) and program research from Center for Interdisciplinary Research, Tohoku University (N.M.).

\section{REFERENCES}

(1). Nasongkla N; Bey E; Ren J; Ai H; Khemtong C; Guthi JS; Chin S-H; A. Sherry D; Boothman DA; Gao, J. Nano Lett.2006, 6, 2427-2430.

(2). Lu W; Singh AK; Khan SA; Senapati D; Yu H; Ray PC J. Am. Chem. Soc. 2010, 132, 1810318114. [PubMed: 21128627]

(3). Koo H; Lee H; Lee S; Min KH; Kim MS; Lee DS; Choi Y; Kwon IC; Kim K; Jeong SY Chem. Commun. 2010, 46, 5688-5670.

(4). Morimoto N; Akiyoshi K Smart Polymer Nano- and Microgels: Synthesis and Applications in The MML Series; Kono K, Arshady R, Eds.; Citus Books: London, 2006; Vol. 8, p 159.

(5). Sasaki Y; Akiyoshi K Chem. Rec. 2010, 10, 366-376. [PubMed: 20836092]

(6). Kabanov AV; Vinogradov SV Angew. Chem., Int. Ed. 2009, 48, 5418-5429.

(7). Oh JK; Drumright R; Siegwart DJ; Matyjaszewski K Prog.Polym. Sci. 2008, 33, 448-477.

(8). Sasaki Y; Akiyoshi K Chem. Lett. 2012, 41, 202-208.

(9). Akiyoshi K; Deguchi S; Moriguchi N; Yamaguchi S; Sunamoto J Macromolecules 1993, 26, 3062-3068.

(10). Akiyoshi K; Deguchi S; Tajima H; Nishikawa T; Sunamoto J Macromolecules 1997, 30, 857861.

(11). Lee KY; Jo WH; Kwon IC; Kim Y; Jeong SY Macromolecules 1998, 31, 378-383.

(12). Nichifor M; Lopes A; Carpov A; Melo E Macromolecules 1999, 32, 7078-7085.

(13). Ozawa Y; Sawada S; Morimoto N; Akiyoshi K Macromol. Biosci. 2009, 9, 694-701. [PubMed: 19291667]

(14). Nagahama K; Mori Y; Ohya Y; Ouchi T Biomacromolecules 2007, 8, 2135-2141. [PubMed: 17559263]

(15). Takahashi H; Sawada S; Akiyoshi K ACS Nano 2011, 5, 337-345. [PubMed: 21138322] 
(16). Morimoto N; Nomura SM; Miyazawa N; Akiyoshi K Polymeric Drug Delivery Vol. II Polymeric Matrices and Drug Particle Engineering; Svenson S, Ed.; ACS Symposium Series 924; American Chemical Society: Washington, DC, 2006; p 88.

(17). Akiyoshi K; Kobayashi S; Shichibe S; Mix D; Baudys M; Kim SW; Sunamoto JJ Controlled Release 1998, 54, 313-320.

(18). Hayashi C; Hasegawa U; Saita Y; Hemmi H; Hayata T; Nakashima K; Ezura Y; Amagasa T; Akiyoshi K; Noda MJ Cell. Phys. 2009, 220, 1-7.

(19). Nochi T; Yuki Y; Takahashi H; Sawada S-I; Mejima M; Kohda T; Harada N; Kong I-G; Sato A; Kataoka N; Tokuhara D; Kurokawa S; Takahashi Y; Tsukada H; Kozaki S; Akiyoshi K; Kiyono H Nat. Mater. 2010, 9, 572-578. [PubMed: 20562880]

(20). Kitano S; Kageyama S; Nagata Y; Miyahara Y; Hiasa A; Naota H; Okumura S; Imai H; Shiraishi T; Masuya M; Masakatsu Nishikawa M; Sunamoto J; Akiyoshi K; Kanematsu T; Scott AM; Murphy R; Hoffman WE; Old LJ; Hiroshi Shiku H Clin. Cancer Res. 2006, 12, 7397-7405. [PubMed: 17189412]

(21). Uenaka A; Wada H; Isobe M; Saika T; Tsuji K; Sato E; Sato S; Noguchi Y; Kawabata R; Yasuda T; Doki Y; Kumon H; Iwatsuki K; Shiku H; Monden M; Jungbluth AA; Ritter G; Murphy R; Hoffman WE; Old LJ; Nakayama E Cancer Immun. 2007, 7, 9. [PubMed: 17441676]

(22). Ayame H; Morimoto N; Akiyoshi K Bioconjugate Chem. 2008, 19, 882-890.

(23). Shin J; Shum P; Grey J; Fujiwara S.-i.; Malhotra GS; Gonzalez-Bonet A; Hyun S-H; Moase E; Allen TM; Thompson DH Mol. Pharm. 2012, 9, 3266-3276. [PubMed: 23030381]

(24). Kim H-K; Van den Bossche J; Hyun S-H; Thompson DH Bioconjugate Chem. 2012, 23, $2071-$ 2077.

(25). Rui Y; Wang S; Low PS; Thompson DH J. Am. Chem. Soc. 1998, 120, 11213-11218.

(26). Boomer JA; Qualls MM; Inerowicz HD; Haynes RH; Patri VS; Kim J-M; Thompson DH Bioconjugate Chem. 2009, 20, 47-59.

(27). Xu Z;Gu W; Chen L; Gao Y; Zhang Z;Li Y Biomacromolecules 2008, 9, 3119-3126. [PubMed: 18834174]

(28). Loethen S; Ooya T; Choi HS; Yui N; Thompson DH Biomacromolecules 2006, 7, 2501-2506. [PubMed: 16961310]

(29). Pine SH; Kim G; Lee V Org. Synth. 1990, 69, 72-75.

(30). Tebbe FN; Parshall GW; Reddy GS J. Am. Chem. Soc. 1978, 100, 3611-3613.

(31). Amundson DM; Zhou MJ Biochem. Biophys. Methods 1999, 38, 43-52.

(32). Tanford C; Buzzell JG; Rand DG; Swanson SA J. Am. Chem. Soc. 1955, 77, 6421-6428.

(33). Akiyosh K.; Sasak Y.; Sunamot J. Bioconjugate Chem. 1999, 10, 321-324.

(34). Akiyoshi K; Ueminami A; Kurumada S; Nomura Y Macromolecules 2000, 33, 6752-6756.

(35). Akiyoshi K; Kang E-C; Kurumada S; Sunamoto J; Principi T; Winnik FM Macromolecules 2000, 33, 3244-3249.

(36). Morimoto N; Winnik FM; Akiyoshi K Langmuir 2007, 23, 217-223. [PubMed: 17190507]

(37). Morimoto N; Qiu X-P; Winnik FM; Akiyoshi K Macromolecules 2008, 41, 5985-5987.

(38). Hirakura T;Nomura Y;Aoyama Y;Akiyoshi K Biomacromolecules 2004, 5, 1804-1809. [PubMed: 15360291] 


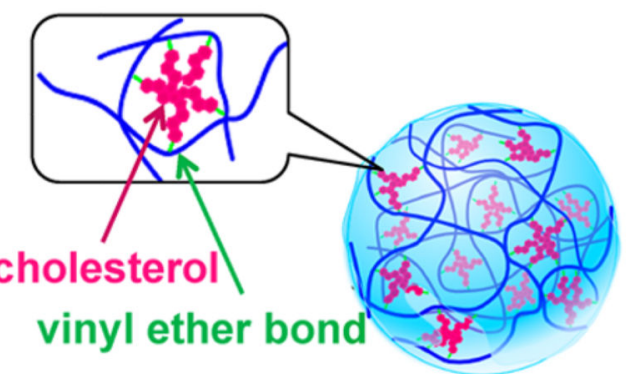

\section{acidic condition}

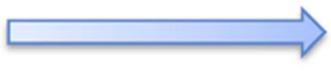

$8-24 h$

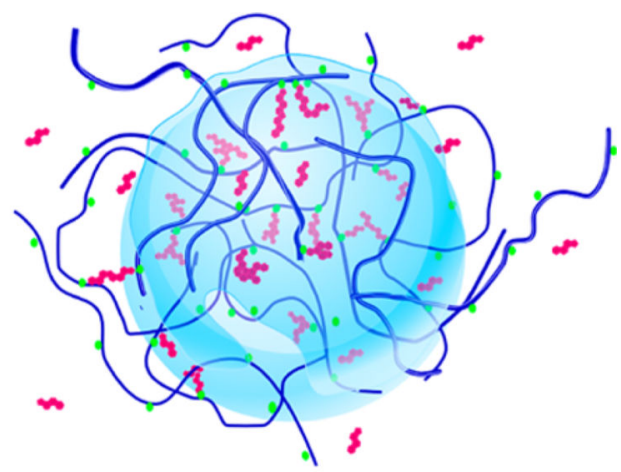

acL-CHP nanogel at $\mathrm{pH} 7.4$

$\mathrm{pH} 4.0$

Figure 1.

Schematic illustration of acL-CHP nanogel at $\mathrm{pH} 7.4$ and 4.0. 

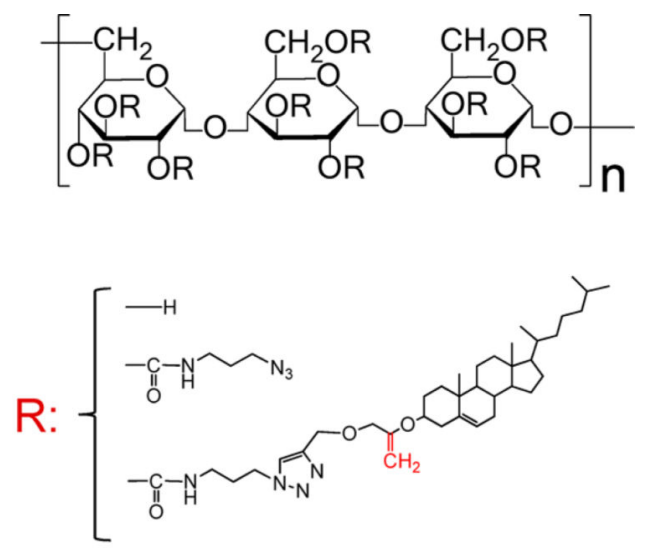

acL-CHP

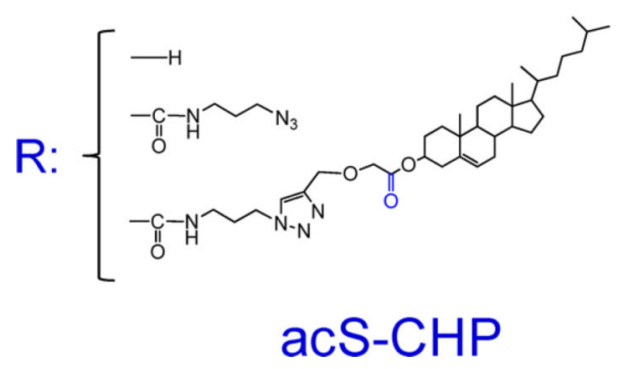

Figure 2.

Chemical structure of acL-CHP and acS-CHP. 
a)

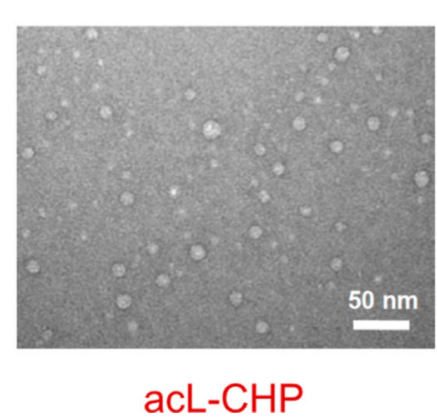

b)

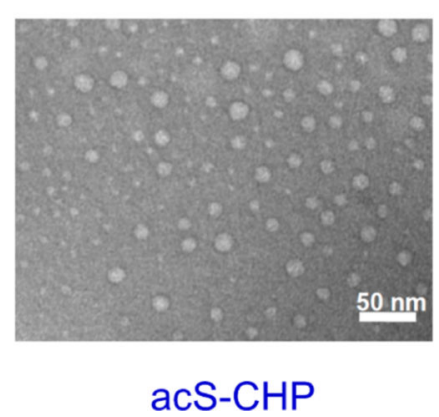

Figure 3.

Negatively stained TEM images of acL-CHP and acS-CHP nanogels in water. 

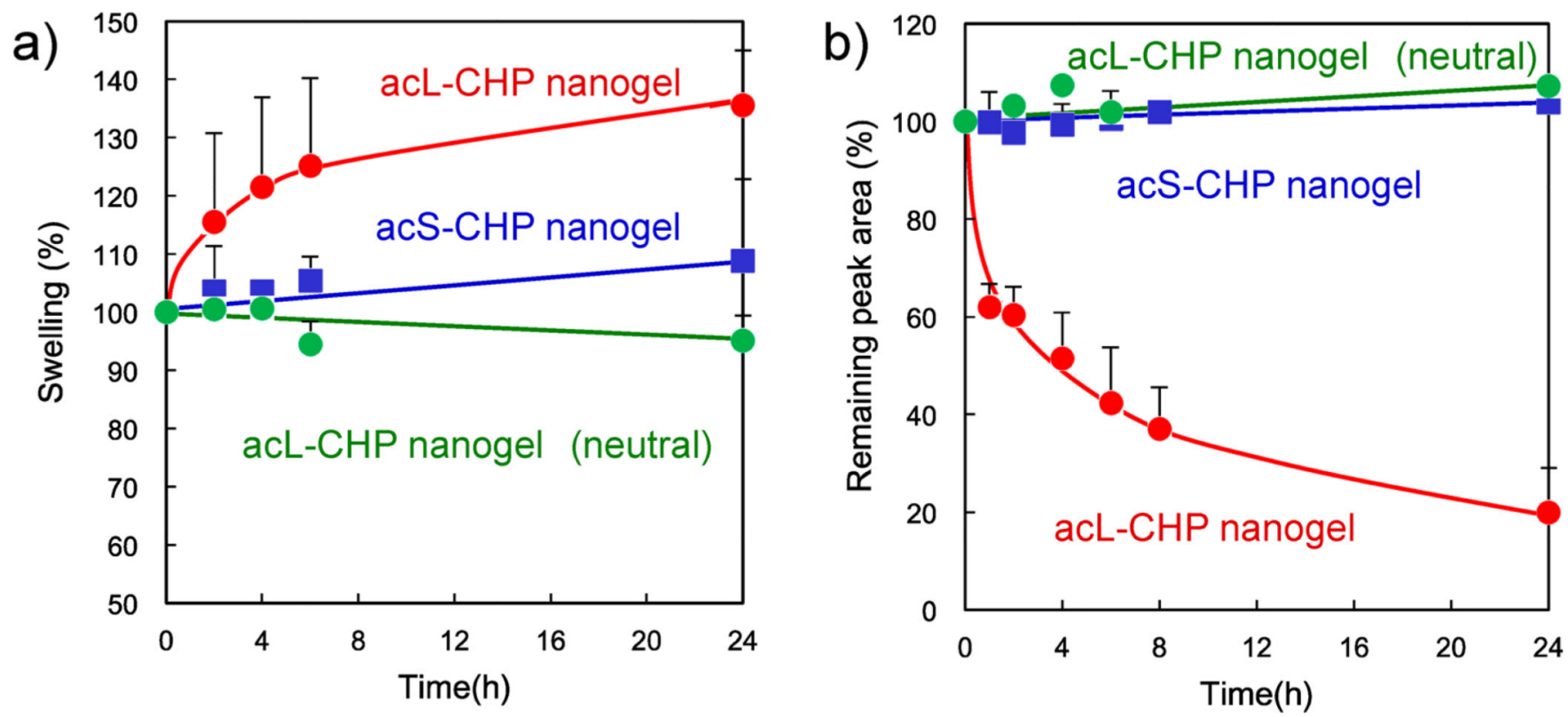

Figure 4.

(a) Swelling behavior of acL-CHP nanogel and acS-CHP nanogel determined by DLS measurements. Red diamond: acL-HP nanoge at $\mathrm{pH}$ 4.0. Green circle: acL-CHP nanogel at $\mathrm{pH}$ 7.4. Blue square: acS-CHP nanoge at $\mathrm{pH}$ 4.0. (b) Peak area, deduced from Figure 5, corresponding to the acL-CHP and acS-CHP nanogel as a function of time. Red diamond: acL-CHP nanoge at $\mathrm{pH}$ 4.0. Green circle: acL-CHP nanoge at $\mathrm{pH}$ 7.4. Blue square: acS-CHP nanoge at $\mathrm{pH} 4.0$. 

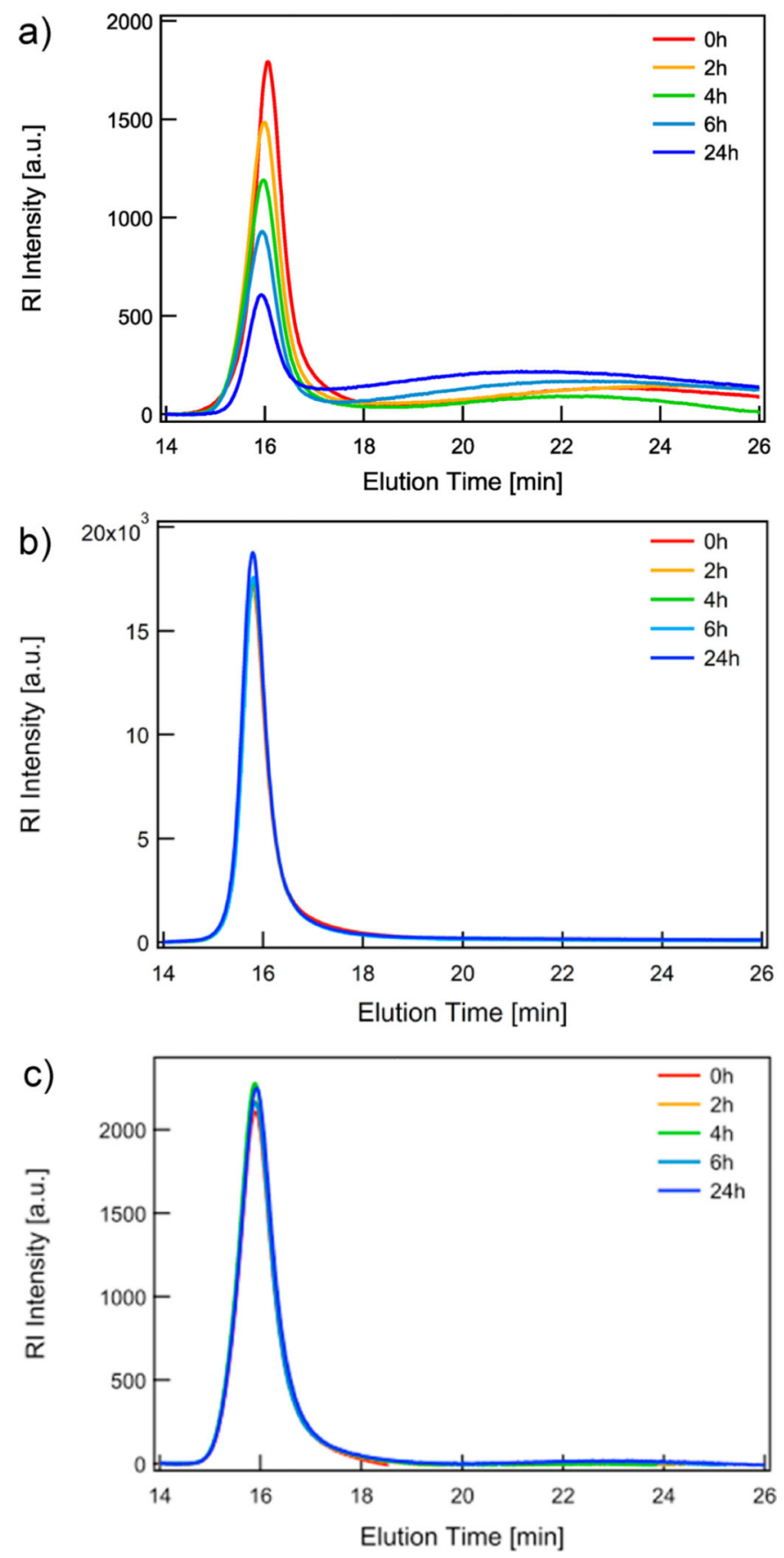

Figure 5.

Chromatogram (RI detection) of time variation of nanogel solutions. (a) acL-CHP nanogel at pH 4.0, (b) acS-CHP nanogel at pH 4.0, and (c) acL-CHP nanogel at pH 7.4. 

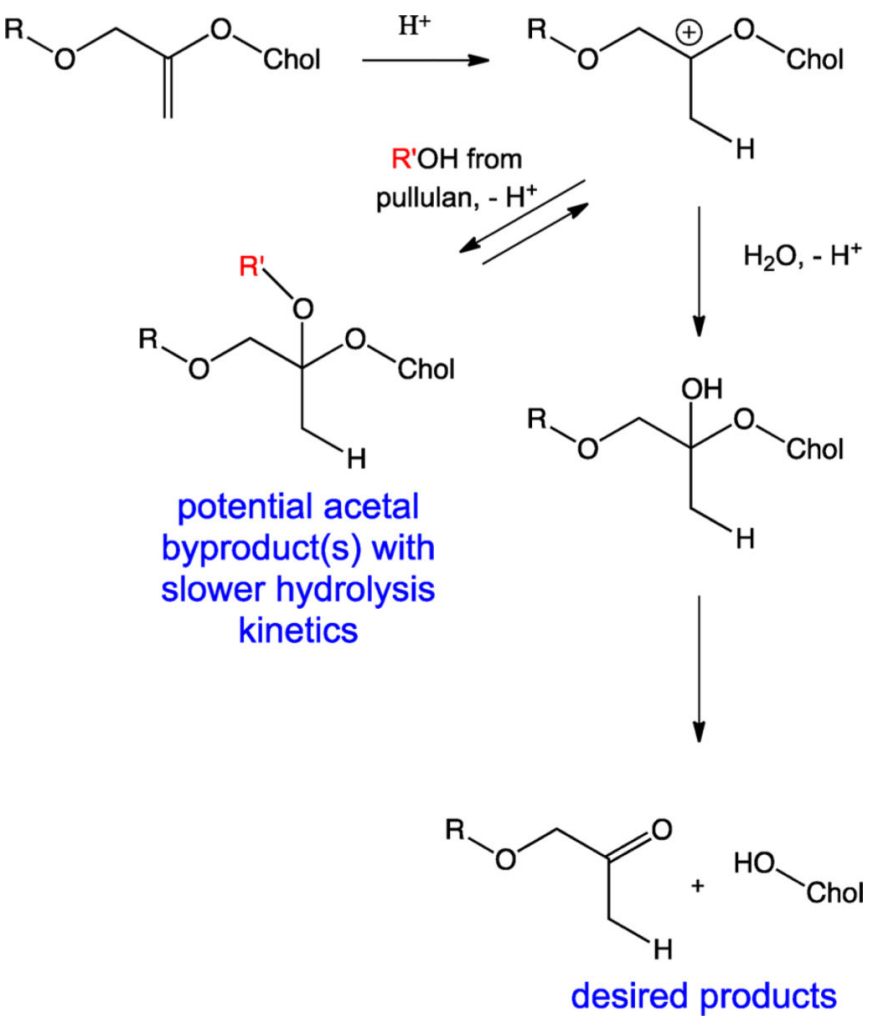

Figure 6.

Proposed reaction kinetics of cholesteryl vinyl ether group hydrolysis under acidic conditions. 


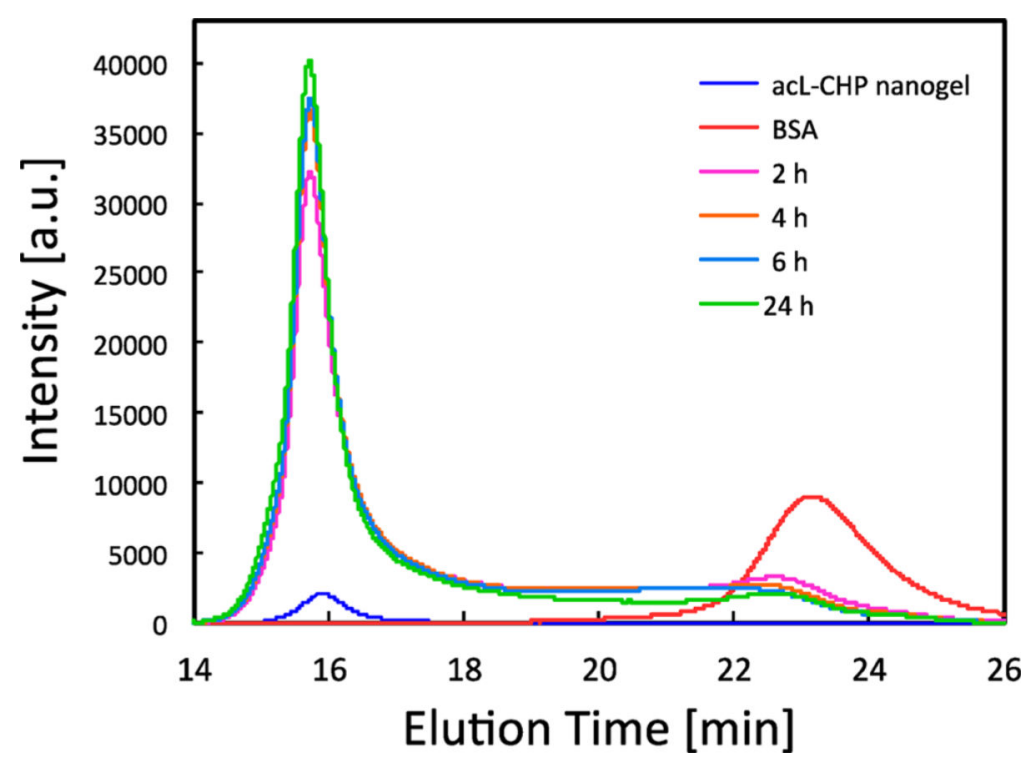

Figure 7.

Complex formation between acL-CHP nanogels and FITC-BSA evaluated by GPC chromatogram (UV-vis detection at $494 \mathrm{~nm}$ ) at pH 7.4. 
a)

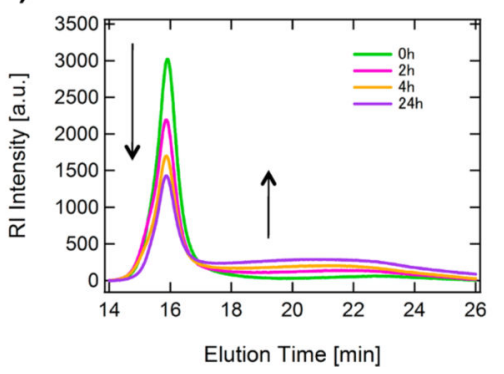

b)

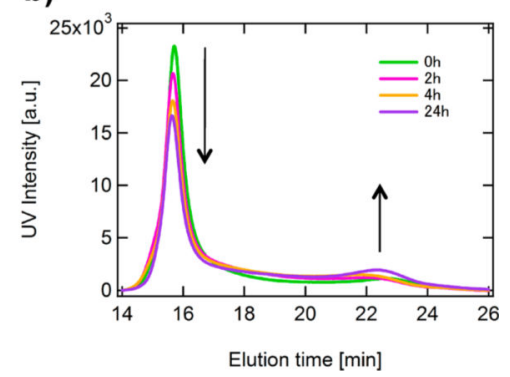

Figure 8.

GPC chromatograms of the complex after treatment at $\mathrm{pH}$ 4.0. (a) RI detection and (b) UV detection at $494 \mathrm{~nm}$. 
<smiles>C#CCOCC(=O)O</smiles>

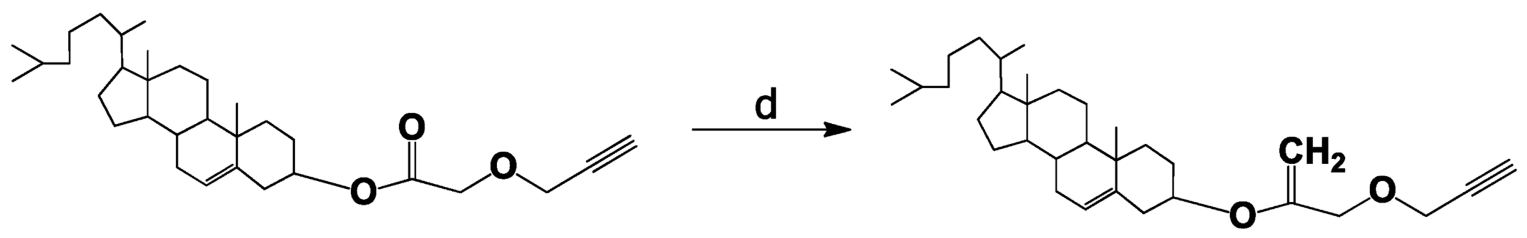

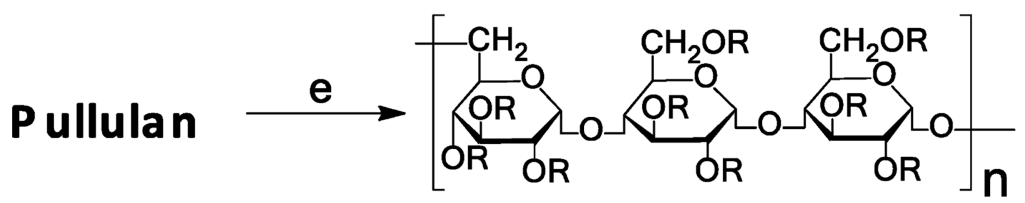
$\mathrm{R}:\left\{\begin{array}{l}-\mathrm{H} \\ -\mathrm{CONH}\left(\mathrm{CH}_{2}\right)_{3} \mathrm{~N}_{3}\end{array}\right.$

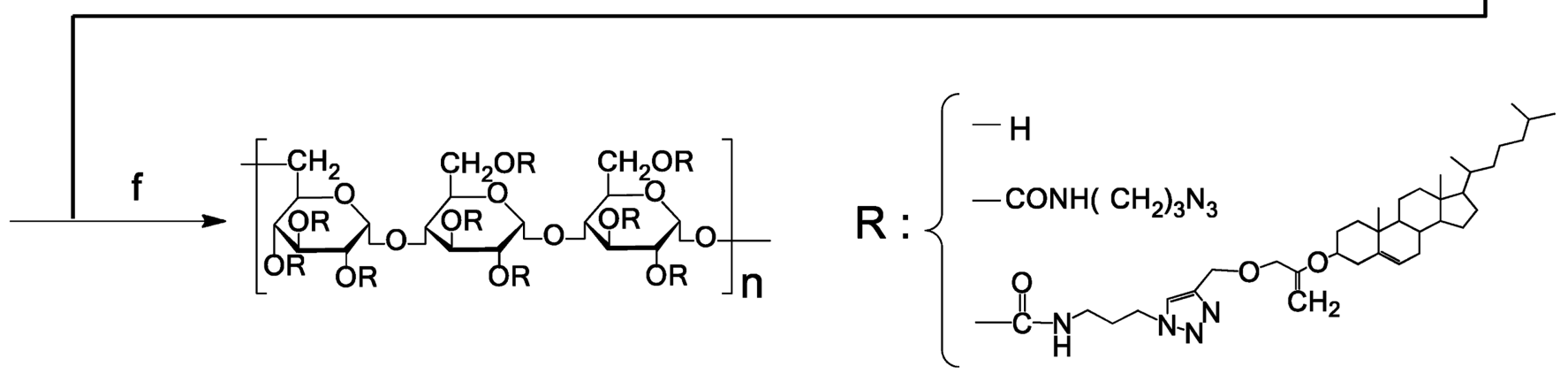

Scheme 1.

Synthesis of acL-CHPa

$\mathrm{a}_{\mathrm{a}} \mathrm{NaH}, t$-butyl bromoacetate, THF, $25^{\circ} \mathrm{C}, 12 \mathrm{~h}$. b: TFA, DCM, $25{ }^{\circ} \mathrm{C}, 1.5$ h. c: DCC, DMAP, DCM, $25^{\circ} \mathrm{C}, 18 \mathrm{~h}$. d: Tebbe reagent, THF/ toluene/pyridine $=1 / 1 / 1,-30{ }^{\circ} \mathrm{C} \rightarrow$ $-10{ }^{\circ} \mathrm{C}$, 2h. e: CDI, 3-azidopropylamine, DMSO, $25^{\circ} \mathrm{C}, 24 \mathrm{~h}$. f: sodium ascobate, copper(II) sulfate pentahydride, $\mathrm{Et}_{3} \mathrm{~N}$, DMSO, $40^{\circ} \mathrm{C}, 5$ days. 
Table 1.

Solution Properties of acL-CHP and acS-CHP Nanogels in Water

\begin{tabular}{cccccc}
\hline nanogel & $\boldsymbol{R}_{\mathbf{H}}(\mathbf{n m})$ & PDI & $\boldsymbol{M}_{\mathbf{W}}\left(\times \mathbf{1 0}^{\mathbf{6}}\right)$ & $\begin{array}{c}\text { association } \\
\text { number of } \\
\text { pullulan }\end{array}$ & $\begin{array}{c}\text { density } \\
\boldsymbol{\Phi}_{\mathbf{H}} \\
(\mathbf{g} / \mathbf{m L})\end{array}$ \\
acL-CHP & $26.5 \pm 5.1$ & 0.25 & 1.02 & 9.6 & 0.022 \\
acS-CHP & $18.5 \pm 1.3$ & 0.22 & 1.13 & 10.7 & 0.071 \\
\hline
\end{tabular}

